\title{
Historia, creencia y convención en Hume y en Ortega
}

\section{History, Belief and Convention in Hume and in Ortega}

\author{
Jaime de Salas Ortueta ${ }^{1}$ \\ Universidad Complutense de Madrid (España)
}

Recibido: 21-06-18

Aprobado: 28-07-18

\section{Resumen}

El artículo realiza una comparación entre Hume y Ortega como autores de historias de la nación. A ello se añade una aproximación entre los dos autores en la medida en que los dos desarrollan teorías de la creencia o convención que constituyen de manera importante la llave metodológica en su visión de la historia. Hume llega a la noción de convención muy tempranamente en el Tratado sobre la Naturaleza Humana, mientras que en el caso de Ortega la aparición de la teoría de la creencia es posterior a la contraposición entre minorías y masa y su muy influyente España Invertebrada. Las diversas crisis de los años '30 le llevan a los conceptos de creencia, de uso e incluso de legitimidad de un orden social. Por ello se puede entender que en Ortega habría una inflexión en su pensamiento por el que, aun defendiendo la unidad europea, entiende que solo desde un concepto de razón narrativa y aceptando las limitaciones de la misma puede situarse el individuo en su momento. Para Hume la Historia de Inglaterra constituye una oportunidad de aplicar conceptos ya trabajados en la primera obra. Es, sin embargo, importante que en la Historia de Inglaterra va a valorar, antes que la propiedad, como en el Tratado, el deber de obediencia.

Palabras-clave: Creencia, Uso, Legitimidad, Historia, razón histórica, Ortega y Hume.

\footnotetext{
${ }^{1}$ (j.desalas.ortueta@gmail.com) Catédratico de Filosofía. Universidad Complutense de Madrid. Ha coeditado el volumen colectivo David Hume, perspectivas sobre su obra (Ed. Complutense) y traducido la Investigación sobre el conocimiento humano (Ed. Tecnos).
} 


\begin{abstract}
The paper approaches Hume and Ortega as authors of historical narratives of their respective societies. This is related to the fact that both developed theories of belief or convention that play an important role in their historical work. Hume arrives at his definitive understanding very early on in the Treatise of Human Nature though in this work property plays an important role. In Ortega's case, his theory of belief is developed in his mature work, after España Invertebrada and La Rebelión de las Masas and the crucial distinction between masses and minorities. It is in the context of the crisis of the thirties that he arrives at the concepts of belief, use, and legitimacy. There is a development of Ortega's thought by which, in order to defend a greater political and social union in Europe, it was necesary for him to abandon a more explicit and intuitive concept of reason, and develop an understanding of reason as narrative, involving both belief and use, for it to be instrumental in man's self undestanding. Hume's History of England is a different case in so far as he applies concepts that he had developed earlier though it is significant that it is obedience, more than property, that appears as the significant convention.
\end{abstract}

Key-words: Belief, Use, Legitimacy, History, Historial Reason, Ortega and Hume.

\title{
1. Introducción
}

Una de las contribuciones más importantes de Hume a nuestra cultura consiste en los seis volúmenes de la Historia de Inglaterra. Desde su terminación en 1762 hasta 1849, cuando la historia de Lord Macaulay la sustituye como la visión más autorizada en la sociedad inglesa de su propia historia, sería la historia de Inglaterra de mayor lectura, publicándose más de 175 ediciones después de la muerte de su autor ${ }^{2}$. Junto a los Dialogos sobre la religión natural esta obra constituye la culminación del proyecto intelectual de Hume.

Me ha parecido oportuno evocar este trabajo relacionándolo con la figura de Ortega y Gasset. Entre la muerte de Hume en 1776 y la Ortega en 1955 median casi dos siglos y en este tiempo el cambio de la sociedad europea con la revolución industrial y las dos grandes revoluciones políticas de finales del siglo XVIII ha sido muy importante. A ello se añade que tratamos de dos autores que se mueven en sociedades distintas, con dinámicas históricas diferentes. Ortega, el más joven, conoció el pensamiento de Hume, pero de una manera, a juzgar por sus escritos, no especialmente pormenorizada ${ }^{3}$. No

\footnotetext{
${ }^{2}$ Sigo los datos en Capaldi y Livingston (1990) p. VII.

${ }^{3}$ La gran mayoría de alusiones a Hume le entienden como empirista seguidor de Locke y cercano
} 
hay desde luego una discusión por parte de Ortega con el filósofo escocés. Con todo, me ha parecido que una confrontación entre ellos en cuestiones internas a la cultura de la Ilustración sería oportuno. Nuestros dos autores plantean lo que pudiéramos llamar proyectos intelectuales antes que sistemas ${ }^{4}$, donde aparte de la contribución que llegan a hacer a unas disciplinas académicas, lo más destacado de su trabajo es la capacidad de orientar a unos lectores cultos sobre su propia realidad social y mostrarles a lo que podían atenerse. En este contexto la historia adquiere un papel importante en las discusiones políticas en la medida en que no solo ofrece un relato empírico de hechos, sino que permite explicar la situación social del momento y depara criterios para juzgarla.

La Historia de Inglaterra de Hume ha ganado mucha atención en los últimos decenios. Ha sido importante la reedición de 1983 de Liberty Fund de un texto que estaba prácticamente olvidado desde la aparición de la Historia de Inglaterra de Lord Macaulay en 1840, pero que previamente, durante un periodo de casi un siglo, había sido la versión más divulgada de la historia de Inglaterra. Aparte de otras cuestiones hay una trama académica en su recuperación. Una parte de esta atención se debe al trabajo de David Lewis (1969) sobre las convenciones, que cita a Hume explícitamente. Snare (1991) y Bricke (1996) han seguido la trayectoria de Lewis. Más recientemente Hardin (2007) y Sabl (2012) han valorado la convención atendiendo más a su importancia en el ámbito de la política. El tema para este último autor no son las convenciones relativas a la justicia, sobre todo a la propiedad que figuran prominentemente en el Tratado de la naturaleza humana, sino a aquellas situaciones que se dan en la historia donde tiene que existir una intervención decisoria con respecto a las convenciones ya existentes.

La Historia debe situarse como continuación no sólo de los ensayos de los años ' 40 y '50 sino como la culminación del trabajo de la gran obra de Hume que es el Tratado. Hume fue un caso excepcional en la medida en que su pensamiento filosófico definitivo se estableció en una obra de juventud. La obra posterior se puede considerar fundamentalmente como la aplicación de

a Berkeley. En cambio, el reconocimiento de persona que valora la opinión pública parece deberse a una lectura del ensayo "On the first Principles of Government" (Hume [E] p. 32). Parece una lectura directa en la medida en que Hume ilustra su posición distinguiendo que la tiranía del sultán de Egipto o del emperador de Roma solo fue posible por contar con la anuencia de los mamelucos o de las bandas pretorianas. En el caso de Ortega se apostilla: "La verdad es que no se manda con los jenízaros. Así, Talleyrand a Napoleón: 'Con las bayonetas, sire, se puede hacer todo menos una cosa, sentarse sobre ellas"” (Ortega [OC] 4-456).

${ }^{4}$ A pesar de que el propio Hume en su prólogo del Tratado mirara con admiración la obra de Newton, hasta el punto de pretender realizar la aplicación de su sistema a las humanidades (Hume [1999] I-93). El subtítulo del título del Treatise reza "siendo un intento de introducir el método experimental de razonamiento en los temas morales". Para el Hume maduro era fundamental el público al que iban destinados sus trabajos. Con todo, retiene la ambición de hacer una historia que tenga en cuenta las causas y no mire únicamente a la ejemplaridad de los personajes. Pocock (1999) p. 184 y 208.

Araucaria. Revista Iberoamericana de Filosofia, Política, Humanidades y Relaciones Internacionales, año $20, \mathrm{n}^{\circ} 40$. Segundo semestre de 2018. Pp. 403-419. ISSN 1575-6823 e-ISSN 2340-2199 doi: 10.12795/araucaria.2018.i40.18 
estos criterios a distintos ámbitos de la cultura. Desde este punto de vista es esencial la noción de convención que introduce en el tercer libro del Tratado y que desempeña un papel fundamental en la Historia. Pero a pesar de esta continuidad hay que tener en cuenta la alteración de la perspectiva que las dos obras toman con respecto a ella. El interés central de Sabl es mostrar "cómo convenciones relativas a la autoridad política surgen, se transforman, mejoran desde distintos puntos de vista y mueren"5. Es decir, la fidelidad a un sistema de gobierno. Y esto implica dejar de lado la óptica del Tratado centrado sobre la propiedad. Las opciones estado-anarquía no se dan normalmente en la vida real de una manera pura. Por el contrario, encontramos diferentes formas de interpretar las convenciones que sólo un tratamiento histórico puede hacer justicia en su concreción y relatar en el curso contingente de la historia ${ }^{6}$. Pueden darse momentos de desfondamiento institucional, pero la historia política de las sociedades modernas mayormente debe consistir en un relato de diferentes convenciones en lo que respecta a la legitimidad que van reformulándose con la marcha de los acontecimientos. Ni el pasado puede desaparecer completamente, salvo en situaciones excepcionales, ni el progreso darse sin más. Por ello la mirada del Hume historiador hacia las convenciones e instituciones constituye una aportación importante. Y es excepcional por estar en todo momento apoyándose en una doctrina sobre la sociedad ya formulada previamente.

Si pasamos al pensamiento de Ortega, la diferencia más visible con el de Hume es que el torso de su pensamiento filosófico es relativamente tardío, y resultado no solo de la atención al desarrollo del pensamiento del momento, sino a su propia práctica intelectual en las postrimerías de la España de la restauración. Si Hume termina el Tratado... con 29 años, Ortega publica Meditaciones del Quijote en el año en que cumplía 31. Pero la distancia que separa, a mi juicio, la primera aproximación de Ortega a la filosofía con trabajos de su pensamiento maduro como La rebelión de las masas, ¿Que es Filosofía? o En torno a Galileo es muy importante y debemos hablar en este sentido de una evolución del pensamiento de Ortega. No se trata de una distancia únicamente temporal de 15 años, sino de una madurez en lo que respecta a cómo entender los conceptos de vida, perspectiva, generación y sensibilidad ya presentes en la obra primera. Dichos conceptos se reformularán posteriormente, veinte años después de Meditaciones ${ }^{7}$. De buscar una fórmula para resumir la comparación, esta sería que la visión filosófica de Hume con el concepto de convención le asiste a la hora de hacer la Historia, que llega por ello a ser una culminación de su pensamiento, mientras que en el caso de Ortega, con un pensamiento consciente

\footnotetext{
${ }^{5}$ Sabl (2012), p. 7.

${ }^{6} \mathrm{Sabl}(2012)$, p. 215.

${ }^{7}$ Debe entenderse que si bien las Meditaciones es un escrito con evidentes marcas nietzscheanas tanto en la forma como en el contenido, en cambio apunta más al neokantismo o la fenomenología en lo que respecta a la doctrina del concepto.
}

Araucaria. Revista Iberoamericana de Filosofia, Política, Humanidades y Relaciones Internacionales, año $20, \mathrm{n}^{\circ} 40$ Segundo semestre de 2018. Pp. 403-419. ISSN 1575-6823 e-ISSN 2340-2199 doi: 10.12795/araucaria.2018.i40.18 
de la importancia de hacer historia ${ }^{8}$, la noción de creencia, menos precisada que en el caso de Hume, solo juega un papel prominente en los últimos veinte años de su producción. Fue desde su experiencia intelectual y a través de trabajos en que analizaba el papel de las minorías en España, España invertebrada, y en Europa La Rebelión de las Masas, como arriba en las nociones de creencia, idea y uso. Así, la distinción fundamental de Ideas y Creencias es tardía. Se precisa en En torno a Galileo de 1933 y en Historia como Sistema e Ideas y Creencias, obras ambas de 1936. Pero al llegar a ese punto, la credibilidad de una acción política con su generación en la sociedad española ya pertenece al pasado.

Ortega nunca renunció a valorar el papel de los intelectuales en la vertebración de una sociedad moderna. Incluso en su obra última seguirá valorando esta función de los intelectuales, pero en una de las grandes obras de su periodo de madurez, El Hombre y la Gente, valorará más la relación interindividual, que se debe salvar frente a la tiranía del uso con el reconocimiento efectivo de que la vida personal emerge de un trasfondo social. Pero en este postrero momento de su carrera ha quedado de lado la acción de la minoría selecta en la sociedad. Al introducir la distinción entre ideas y creencias Ortega da paso a la valoración de un elemento que se encuentra allende de la conciencia explícita de los intelectuales. Consciente de la importancia de las ideas, el Ortega maduro se apoya ante todo en una visión de lo creencial. Por ello, para valorar la cultura en toda su medida es importante la neutralidad de un historiador antes que la acción ideológica de quien pretende lograr para las minorías de su país una nueva sensibilidad. Esa es la neutralidad en la que Hume, en su proyecto histórico, se encuentra instalado. La comparación entre los dos filósofos es oportuna, pues hay que recalcar que los dos autores están empeñados en defender una concepción de la historia que permita comprender el presente.

\section{La valoración de la propia sociedad y la tarea de la historia}

En 1752, en uno de sus ensayos "Sobre la sucesión protestante", escribe Hume sobre la sociedad inglesa del momento: "No hay otro caso en la historia de la humanidad en que tantos millones de personas, en tanto tiempo, se han mantenido unidos de una forma tan libre, tan racional, y tan ajustada a la dignidad de la persona humana". En cambio, la valoración que hace Ortega

\footnotetext{
${ }^{8}$ Su tesis doctoral fue sobre "Los temores del año mil". En Meditaciones del Quijote, la Meditación primera era un Breve tratado sobre la novela donde la modernidad se establece con la innovación que la novela representa.

${ }^{9}$ Hume (1987) p. 276. Asimismo, E 276: -“Las libertades de Inglaterra, lejos de decaer con la mejora de las artes y de las técnicas, han florecido más que en ningún otro momento- el progreso en las artes y las técnicas es favorable para la libertad y tiene la tendencia a conservar, cuando no producir, un gobierno libre".
} 
de su sociedad, la española de comienzo del siglo XX, es distinta. En un texto escrito cuando no había cumplido 25 años nos encontramos lo siguiente:

\begin{abstract}
“necesitamos precisamente ser una nación. Hoy no lo somos, en el sentido pregnante de la palabra: hoy se nos tomaría más bien por una manada de antropoides recluida en un extremo de Europa, tiritando de puro frío moral bajo un sol ancho y recio, últimos ejemplares de una fauna humana incapaz de perdurar en el clima moderno. Para elevarnos a nación tenemos que unirnos en un ideal moderno" $"$.
\end{abstract}

Ya aquí la idea de la nación es algo por hacer. Mientras que en Hume la complacencia por el estado de su nación no es un tema que aparezca con gran frecuencia, aunque sí condicione sus Ensayos e Historia de Inglaterra, en Ortega el tema de España es central en su obra anterior a 1932. Escribe para una opinión culta que preconizaba una "reforma intelectual y moral" de la sociedad que nos acercara a las naciones más desarrolladas de la Europa del momento.

Hay tres diferencias entre los dos autores en este punto. En primer lugar, el juicio matizadamente positivo de Hume con respecto a su nación contrasta con el negativo de Ortega en lo concerniente a España. Para el uno, era una situación que ocasionalmente hace constar y que no evita la conciencia de que puede darse una coyuntura desfavorable que revoque lo conseguido. En cambio, construir una nación parece para Ortega una tarea importante que recae sobre la propia generación, un tema para su tiempo por emplear el título de una de sus obras ${ }^{11}$. En segundo lugar, siendo en los dos casos la valoración de la propia sociedad una experiencia central, incide desde luego más en el desarrollo de la visión teórica de Ortega que en la de Hume. No se trata solo de constatar una situación en el caso del pensador español, sino de poner su pensamiento al servicio de la superación de ese diagnóstico negativo. Finalmente, la tonalidad de las dos obras está en gran medida condicionada por esta experiencia. Efectivamente, cabe mirar al presente de su sociedad con determinada serenidad aceptando la contingencia de los hechos históricos y la posibilidad de que su situación cambie, pero al tiempo aceptando lo logrado ecuánimemente como Hume. En cambio, en el caso de Ortega la reflexión tiene que plantearse en primer lugar la reforma de la cultura y de la sociedad, que a su vez condicionaría la vida

${ }^{10}$ OC 1-210. Otro texto de 1912 anticipa la posición madura de las Meditaciones del Quijote: "Se busca a España como sujeto de un triunfo y claro está, cada paso en esa dirección aleja más a la conciencia nacional del misterioso lugar donde su secreto yace. Hay que buscarla como sujeto de un fracaso. Sólo la trágica emoción del fracaso nos conducirá en vía recta por la selva multisecular de las apariencias históricas hasta el punto donde sintamos latir, donde veamos sangrar la pobre víscera cordial de la raza española". Esta posición negativa con respecto a la historia de España se mantiene en España Invertebrada 10 años después. También aquí Ortega trabaja con un razonamiento derivado de una interpretación de la historia de nuestro país y referida a la ausencia de minorías selectas.

11 El título de Ortega está pensado para la cultura europea en general, pero de una manera más próxima es la que tendrían que emprender una generación de españoles. Un ejemplo cercano es la Liga de la educación política española (VII-328), gestionado al tiempo que redacta Meditaciones del Quijote.

Araucaria. Revista Iberoamericana de Filosofía, Política, Humanidades y Relaciones Internacionales, año 20, $\mathrm{n}^{\circ} 40$. Segundo semestre de 2018. Pp. 403-419. ISSN 1575-6823 e-ISSN 2340-2199 doi: 10.12795/araucaria.2018.i40.18 
política. Hay un énfasis moral en la obra de Ortega. Se parte de una conciencia de la ausencia de excelencia e incluso de un sentimiento de vergüenza colectiva que la sociedad tiene que superar. La coyuntura pone a prueba los resortes morales de la sociedad en el caso del filósofo español, mientras que la Historia de Inglaterra se redacta con el ánimo de entender mejor el proceso que ha seguido la sociedad inglesa, las raíces políticas de ese relativa paz después de un turbulento siglo XVII y la necesidad de una política de consenso a la que se había llegado.

Desde este punto de vista, el texto de juventud arriba citado de Ortega introduce un eje constante de su obra. Por ejemplo, el concepto de una España posible estaría detrás de Meditaciones del Quijote:

\begin{abstract}
"de entre los escombros tradicionales, nos urge salvar la primaria sustancia de la raza, el módulo, aquel simple temblor español ante el caos. Lo que suele llamarse España no es eso, sino justamente el fracaso de eso. En un grande, doloroso incendio habríamos de quemar la inerte apariencia tradicional, la España que ha sido, y luego entre las cenizas bien cribadas, hallaremos como una gema iridiscente la España que pudo ser"12.
\end{abstract}

En este punto se puede reconocer una continuidad desde Meditaciones del Quijote, España invertebrada, los escritos que se redactan en el contexto de la crisis de la Restauración y el advenimiento de la segunda república española -La redención de las Provincias y Rectificación de la Repúblicapara culminar en el Prólogo a una edición de sus obras. Mantienen a España como el tema más importante de su trabajo intelectual. A la altura de 1932 Ortega afirma que "toda mi obra y toda mi vida han sido servicio de España"13.

Hay una serie de conceptos que, en Meditaciones del Quijote, pero también en otras obras posteriores, se introducen con la intención de proponer una solución a la insatisfacción que la sociedad produce mediante la acción consciente de los ciudadanos. Nos limitaremos a enunciar los más importantes, señalando que ganan especial sentido por la función que tienen dentro del proyecto intelectual de Ortega; así, incluiríamos perspectiva, sensibilidad, ideología, integración, minoría, masa, particularismo, proyecto y mando. Además, hay que reseñar también el trasfondo nietzscheano de vitalismo con el que se trata de dinamizar la realidad social. Tanto por esta adscripción a un vitalismo, como por el esfuerzo por utilizar la fenomenología, y finalmente por

12 OC 1-793. La alusión a la España posible está anticipada en la "plenitud" que la obra busca desde su primera página (OC 1-747). El mismo principio se mantiene negativamente: "la muerte de lo muerto es la vida" (OC I-759). Es un ejemplo del uso prospectivo y político de la historia que responde a la conocida pregunta: "Dios mío, ¿Qué es España? ¿Dónde está -decidme- una palabra clara, una sola palabra radiante que pueda satisfacer a un corazón honrado y a una mente delicada, una palabra que alumbre el destino de España?" (OC I-791).

13 OC V-96. 
la búsqueda de crear -más que atender- una opinión pública de orientación progresista, que ayuden a superar una situación social negativa, el proyecto de Ortega difiere del de Hume.

En el caso del filósofo español, en este periodo de su actividad previo a 1932 la regeneración tiene que tener lugar gracias a la acción de los ciudadanos, o por lo menos de las minorías con el apoyo del conjunto de la sociedad. En cambio, en Hume hay la conciencia de una continuidad donde se puede lograr un consenso político amplio como tuvo lugar en su tiempo, o perderlo como había ocurrido en el reinado de los dos primeros de los reyes Estuardos. Sobre todo, la posición de Hume es la del narrador que adopta distintos puntos de vista para presentar los acontecimientos. Mientras que la ambición política de Ortega es lograr elevar el nivel de la vida nacional ante la constatación de su retraso por comparación a otros países europeos, y en ello se encuentra centrado su proyecto, en el caso de Hume el logro relativo de la Inglaterra de su tiempo no evita que "en todos gobiernos hay una lucha permanente e interna, abierta u oculta, entre autoridad y libertad, y ninguno puede prevalecer completamente en este enfrentamiento"14. En ese sentido, una cosa es la seducción del gobierno de turno y la integración que la política debe conseguir en torno a "un proyecto sugestivo de vida en común" 15 que preconiza Ortega. Otra es la visión de Hume de la permanente tensión, incluso rivalidad que recorre la historia inglesa entre monarquía y pueblo.

No solo Hume cree que el desarrollo de la historia es azaroso y los cambios de nivel entre sociedades y países, revocables, sino que en el centro de su percepción de la política está la constatación de diferencias que solo se pueden atenuar momentáneamente. En cambio, en el caso de Ortega, sin desconocer el carácter específico de la sociedad española, hay una voluntad de lograr que la sociedad llegue a estar al día y ajustada a las posibilidades del momento. La buena política en el caso de Hume permite que las fuerzas de una sociedad se desarrollen por sí solas, mientras que para Ortega se trataría de la llegada al nivel de otros gracias a la acción de unas minorías. Ciertamente, Ortega sabía bien que la introducción de nuevos modelos y procedimientos no se puede hacer sin tener en cuenta la realidad de la misma sociedad. Por ello, la circunstancia a la que apela en Meditaciones del Quijote es una concreta, situada, de acuerso con sus propias metáforas, entre los puertos del Guadarrama y el campo de Ontígola ${ }^{16}$, pero la misma acción de aplicación y actualización de ideales foráneos es fundamental para el madrileño, una actualización no solo política, sino social.

\footnotetext{
${ }^{14}$ Hume (1987), p. 40.

${ }^{15}$ OC III-442.

${ }^{16}$ OC I-756. Cfr. también las observaciones en el comienzo de Misión de la Universidad IV-533.
} 
En épocas distintas los dos autores se interesan por la creencia y la convención y de maneras diferentes entienden que la historia es también la historia de las mismas. Esta visión interviene en sus respectivas visiones de la historia.

\section{Creencia y Convención en la historia}

Con motivo de la concepción de la historia de Ortega podemos apreciar dos formas distintas aunque relacionadas de hacer historia. Una sería la historia que practica España Invertebrada, que se atiene fundamentalmente a la historia política y social, pero al tiempo tenemos estudios específicamente sobre géneros e ideas como es el Breve Tratado sobre la novela de Meditaciones del Quijote o El Tema de nuestro tiempo, que encuentra su continuación en En torno a Galileo y culmina en El Epílogo a la Filosofía o La idea de principio en Leibniz. En estos trabajos, la idea de creencia marca un avance en el pensamiento de Ortega en la medida en que a partir de En torno a Galileo la historia intelectual pasa a ser historia de la dinámica de ideas y de creencias con el supuesto de que la vida social debe entenderse fundamentalmente como la sucesión de creencias que al perder vigencia van siendo sustituidas por nuevas ideas. Con respecto a las convenciones, la actitud de Hume es distinta en la medida en que no se fija tanto en la capacidad creativa de los individuos o de la sociedad que puede caracterizar la historia intelectual, sino que en la Historia de Inglaterra, entiende la sociedad como redescribiendo determinadas convenciones y oposiciones dentro de un pluralismo real ${ }^{17}$. Hay nuevas épocas pero las novedades vienen a ser adjetivas a una realidad que se presenta como un movimiento permanente por salir de la barbarie feudal y definir un ámbito donde libertad y autoridad convivan. Al consistir el papel de la minoría selecta en Ortega en que el proyecto de nación pudiera ser aceptado y funcional, la coyuntura exige que la lucha por el poder en que consiste la vida de una sociedad se comprenda fundamentalmente desde ese imperativo de renovación. En cambio, los acuerdos de 1688 y de 1714 en Inglaterra que llevan hasta el trono a Guillermo de Orange y a Jorge I de Hannover permitieron establecer un consenso que condujo a la estabilidad que Hume refleja en el texto citado, y dio lugar al crecimiento del país en su conjunto.

\footnotetext{
${ }^{17}$ Hume (1987), p. 339 "A lo largo de 4 reinados (los de los reyes estuardos) hubo un permanente enfrentamiento entre la corona y el pueblo. Privilegio y prerrogativa real estaban en liza, y ambos bandos además del tema concreto del que se disputaba tenían muchas reclamaciones pendientes que en el momento adecuado producirían en contra de sus adversarios". Se entiende por privilegio los derechos que la Magna Carta consagró y por prerrogativa la ascendencia de la Corona especialmente durante el siglo anterior con los reyes tudores.
}

Araucaria. Revista Iberoamericana de Filosofia, Política, Humanidades y Relaciones Internacionales, año 20, $\mathrm{n}^{\circ} 40$. Segundo semestre de 2018. Pp. 403-419. ISSN 1575-6823 e-ISSN 2340-2199 doi: 10.12795/araucaria.2018.i40.18 
A la hora de comprender por qué unas creencias consiguen vigencia, el papel de las minorías adquiere especial importancia para Ortega y la visión de España Invertebrada o La Rebelión de las Masas no queda atrás, pues aquellas son las que tienen que renovar la cultura. Pero ahora en la obra madura el énfasis se pone más en el contenido de la acción, la nueva creencia, y no en el sujeto. En cambio, en la descripción de las convenciones por parte de Hume no se sigue una comprensión hegeliana de la cultura por la que se trata de un producto de trama histórica, sino de expresiones de la naturaleza humana que pueden ir cambiando en su forma.

No podemos desarrollar de manera amplia la temática central de la contraposición entre Hume y Ortega, sino que nos tendremos que limitar a esbozar tres epígrafes distintos:

1.- ¿En qué consiste el vínculo social que la política debe mantener?

2.- La caracterización de una metodología histórica por parte de estos autores.

3.- La historia como instancia intermedia en el racionalismo y el conservadurismo.

1- Hardin entiende que ha habido antes de Hume tres métodos de entender la unidad de una sociedad ${ }^{18}$ : el respeto a un contrato, el reconocimiento del derecho divino de los reyes y el miedo a la represión. Hume añade una cuarta que sería el poder de la convención, es decir, el sistema de creencias y vigencias con los que los miembros de dicha sociedad se identifican. Por supuesto, la teoría de la creencia como se introduce en el primer libro del Treatise, y que ha conseguido mayor atención, constituye uno de los grandes hitos del primer empirismo, al poner en cuestión la racionalidad de las inferencias causales. Pero, en realidad, es secundaria a una visión de la realidad del hombre compartiendo un espacio social con sus semejantes en virtud de la aceptación, incluso la identificación con un determinado orden ${ }^{19}$. Siendo más importante la visión de la convención del libro III, esta puede producir rechazo en el lector actual por la voluntad de seguir de cerca una justificación psicológica que se apoya en la asociación de ideas que, por otra parte, sería completamente ajena a las implicaciones del "linguistic turn" de la filosofía anglosajona de nuestro tiempo. Pero más alla del método está la intuición clara de que la inserción del individuo en su realidad social pasa por unas identificaciones culturales que casi resultan tan determinantes para él como la del lenguaje $\mathrm{e}^{20}$.

\footnotetext{
${ }^{18} \operatorname{Hardin}(2007)$ pp. 81 y ss.

${ }^{19}$ Schmidt (2003), 260.

${ }^{20}$ También es importante en este contexto la contribución de Baier (1985), (1994) y (2010) que abunda especialmente en la confianza como virtud que permite la integración social. Independientemente del enorme interés de los trabajos de esta especialista, he querido desarrollar el 
Ortega tiende a dividir la realidad social en función del hombre masa y del individuo egregio, y a entender que el equilibrio de una sociedad viable históricamente se encuentra en la capacidad de mando de las minorías. Ciertamente, se trata de un mando "sugestivo" y no violento. En el caso de Ortega se relaciona con el concepto de mando, aunque a su vez tiene una dimensión creencial clara. Por ejemplo, con motivo de Roma Ortega entiende que "la sustancial concordia implica, pues, una creencia firme y común sobre quien debe mandar" ${ }^{21}$, pero además el mando apunta a la iniciativa que, según Ortega, una minoría debe tomar dentro de una sociedad. También el mando puede representar el peso de la sociedad, que por ella misma mantiene sus propios usos en la medida en que por el conjunto recuerde -a veces imperfectamentelo que una acción personal ha establecido. Se convierte entonces en uso. Lo característico de Ortega al buscar ante todo la modernización de la sociedad española en el periodo de 1914 a 1932 es entender que ésta se consigue por la presentación, divulgación y discusión de nuevas propuestas. La visión dinámica de Ortega contrasta con el carácter estático de una visión dominada por la naturaleza.

2.- En Hume, la amplitud de la convención es enorme por estar unida a la acción, recordando la imagen de Wittgenstein del juego del lenguaje que integra elementos heterogéneos: actos y pensamientos verbalizados. El comportamiento del hombre se describe por la asociación de ideas, pero dicho mecanismo, que opera puntualmente en el tiempo, está remitiendo permanentemente a un contexto de creencias y expectativas previamente establecidas como el contexto que orienta la vida social en general. Sería una forma de a priori empírico compartido por los miembros de la comunidad en cuestión. La vida cotidiana en todas sus manifestaciones remite a ese código implícito, acumulado en la memoria de los hombres, por el que el significado de sus actos se encuentra en gran medida definido por un conjunto de convenciones previas. Se trataría de una estructura creencial que actuaría cual segundo lenguaje, permitiéndole al hombre situarse en su realidad, comunicarse y actuar con otros hombres, y en definitiva gestionar su propia vida. Hume se limita a describir lo que ocurre en principio en la sociedad. Con la noción de convención integra tanto los actos como su sentido para quienes participan de ellos.

En este sentido, la contraposición de Ortega de usos frente a actos propiamente personales para delimitar el ámbito de lo social tiende a desconocer que el ámbito de las creencias se extiende más allá del mundo de las grandes ideas e impregna de hecho la vida social en general. El contexto

tema en el contexto de la Historia de Inglaterra y una determinada clase de convenciones que Hume relaciona con la noción de justicia.

21 OC 4-456. 
de Ideas y Creencias parece ser más bien lo que llamaríamos las ideas teóricas últimas, aunque encontramos ejemplos de la realidad de las creencias en actos cotidianos. También es verdad, como hemos visto, que hay algunas que se refieren a la organización de la sociedad, es decir a quién debe ejercer el mando. En principio, habría que decir que los textos orteguianos apuntan con mucha eficacia hacia la realidad de lo que se da por supuesto sin atender propiamente a la acción consiguiente cuando la noción de convención incluye los dos momentos.

En cambio, en el caso de Hume habría una delimitación de convenciones que necesariamente implican interacción social ${ }^{22}, \mathrm{y}$ artificialidad en el sentido de respeto a un orden vigente y convencional. La acción humana desde la obra de Hume está orientada hacia la aceptación de dichas convenciones. Las creencias del libro 1, por las que Hume es más conocido, mantienen unos rasgos comunes con las convenciones cuya descripción más detallada aparece en el tercer libro de la obra a propósito de la virtud de la justicia. En los dos casos se trata de explicar la naturalidad con que se siguen proposiciones, que serían vistas como leyes de la naturaleza, bien aquellas a las que atiende la ciencia bien las que sigue la sociedad. La diferencia estaría en que en el libro 1 las percepciones son "originarias", mientras en los libros 2 y 3 son secundarias en la medida en que en la experiencia aparecen las pasiones. De esta forma se podría establecer un paralelismo entre la legitimidad de una convención y el fundamento de una inferencia causal, en tanto que ambas remiten al hábito y a la reiteración de la experiencia ${ }^{23}$. Asimismo se da algo semejante entre la conciencia de una conexión necesaria entre causa y efecto y el carácter vinculante de la obligación ${ }^{24}$.

En lo que respecta a la metodología histórica por parte de estos autores hay que advertir que la obra de Hume destaca tanto en lo que respecta a la definición de esta metodología como en su aplicación a los hechos históricos. El gran problema del concepto en Meditaciones del Quijote y de la creencia en el pensamiento último de Ortega es la caracterización de su contenido. La presentación de la misma en Ideas y Creencias es eficaz en la medida en que se ejemplifica bien la distinción entre los dos principios, pero deja en pie el problema de determinar cuáles son las creencias efectivas de una sociedad que en principio los mismos individuos pueden ignorar o no tener propiamente tematizadas. En cambio, las convenciones se traducen fácilmente en actos al ser mucho más susceptibles de descripción. Así, entre el concepto de convención

${ }^{22}$ En el caso de Ortega hay un castigo social por no seguir los usos establecidos, pero el panorama que abre los análisis de Hume es el de un conjunto de reacciones de muy distinta índole ante un comportamiento, lo que sería parte de la riqueza de la sociedad: coordinación, contraposición, etc. que a su vez se apoyan en convenciones (Sabl [2012] p. 9).

${ }^{23}$ Hume (2007), 3.2.2, p. 319, por comparación a la "constant conjunction" de 1.3.6, p. 61 (Sabl [2012], p. 150).

24 Hume (2007), 1.3.14, p.111.

Araucaria. Revista Iberoamericana de Filosofía, Política, Humanidades y Relaciones Internacionales, año 20, $\mathrm{n}^{\circ} 40$. Segundo semestre de 2018. Pp. 403-419. ISSN 1575-6823 e-ISSN 2340-2199 doi: 10.12795/araucaria.2018.i40.18 
que utiliza Hume y la creencia que defiende Ortega se encuentran un cierto desemparejamiento: si bien la mayoría de los actos del individuo tienen unos presupuestos creenciales y convencionales y de su observación podemos inferir la existencia de estos últimos, en cambio es difícil pasar de creencias a actos concretos: la creencia analizada abstractamente tiene una realidad disposicional que de hecho puede o no conducir a acción en cada circunstancia. Mientras que la acción se puede describir y por lo general no es difícil asignarle sentido y dimensiones creenciales, el paso de la creencia al hecho es menos claro, porque presupone la intervención de ese mismo sujeto. Cabe, como hace la Historia de Inglaterra, que el historiador describa la evolución de la convención de la asignación de poder en la sociedad, mostrando cómo ha sido redescrita en un momento dado y también cómo en determinados momentos la misma sociedad se encuentra dividida por la manera en que esta convención es interpretada. En los relatos de Ortega no se llega a tanto detalle. Se alude más al hecho de que en determinadas coyunturas las creencias ya no son funcionales y es necesario introducir ideas nuevas que pueden llegar a convertirse en creencias. Además, Ortega tiende ante todo a atender a determinados casos de ideas de contenido científico y filosófico y a apartarse de la gestión de la vida cotidiana.

Tanto las convenciones como las creencias no sólo de hecho sustentan la convivencia social e implican una parte importante del contenido significativo de las interacciones que tienen lugar entre las personas. Asimismo determinan las posibilidades que una sociedad tiene en un momento determinado. La noción de "circunstancia" en Meditaciones del Quijote le permite a Ortega hablar de una España posible que estaría fundada en la misma realidad de la sociedad española. El ocaso de las revoluciones constituye una crítica de la razón pura y anticipa la búsqueda de Ortega de una razón histórica en Historia como Sistema y en los primeros capítulos de En torno a Galileo, pero aquí también, aun cuando se puede entender que la aceptación de nuevas ideas que llegan a adquirir un carácter creencial, va a depender de una afinidad con las creencias que no han sido directamente afectadas por la erosión cultural de una sociedad. En algún pasaje Ortega escribe sobre un sistema, pero en realidad no se trata de un sistema en el sentido matemático del termino. Ciertamente, Ortega no piensa en un sistema de ideas, sino que parece consciente del peso de una perspectiva en el que las creencias tienen una realidad disposicional ${ }^{25}$. No es un sistema ciertamente. Sería más ajustado hablar de composibilidad, es decir de no exclusión o incompatibilidad. Un autor interesante en este punto es Tocqueville, que en su esfuerzo por dar con las razones para buscar la posibilidad de la democracia, compara la Constitución de Estados Unidos, como integrada en la cultura de la sociedad para la que fue ideada, con la Constitución

\section{${ }^{25}$ O.C. VI-48}

Araucaria. Revista Iberoamericana de Filosofia, Política, Humanidades y Relaciones Internacionales, año $20, \mathrm{n}^{\circ} 40$. Segundo semestre de 2018. Pp. 403-419. ISSN 1575-6823 e-ISSN 2340-2199 doi: 10.12795/araucaria.2018.i40.18 
mexicana, que no guarda relación con la cultura efectiva de su sociedad. Hace falta que un texto legal, como la constitución con los valores a los que apela, pueda ser asumida, al menos en parte, por el cuerpo social para el que se estableció. De lo contrario, la vida política sería en principio sólo una representación vacua de la misma sociedad. "Los habitantes de México, queriendo establecer un sistema federal, tomaron como modelo y copian casi totalmente la Constitución federal de los angloamericanos, sus vecinos. Pero al incorporar la letra de la ley, no pudieron introducir el espíritu que la vivifica" 26 . En ello remite Tocqueville a su concepto de "moeurs", hábitos, que mantiene una relación con "convenciones" y "creencias". Entiende "les moeurs" como "una de las grandes causas generales a las se pueden atribuir el mantenimiento de la república democrática en Estados Unidos"27.

Finalmente, el desarrollo de una teoría de los usos en una de sus últimas obras, El Hombre y la Gente, introduce una contraposición entre vida personal y vida social que tiende a dejar en segundo plano el que la vida individual y personal se desarrolla a partir de la aceptación e interpretación de los usos, empezando por el mismo lenguaje, aunque claramente Ortega no desconocía este hecho. La representación de un escenario de presión social sobre el individuo puede justificar esta distinción, pero la valoración de las creencias en otros textos expresa mejor la manera en que el individuo se desarrolla como tal a partir de una cultura compartida. Mientras que el uso en Ortega se entiende como una imposición de la sociedad, el modelo humeano más bien resalta la libertad de quien elige seguir una convención en su comportamiento pudiendo abstenerse de hacerlo con la advertencia de que para la sociedad la posibilidad de esta elección es fundamental para el orden general. El tomar compromisos o cumplir la propia palabra es valorado positivamente, y no se entiende por parte de Hume que se trata de un comportamiento que solo vale dentro de la vida interpersonal.

En cualquier caso se cumple también en Hume la expresión de Ortega de que nuestras creencias y convenciones constituyen nuestra realidad.

3.- Hume y el último Ortega coinciden al entender que el conocimiento histórico atenúa la radicalización de las ideas. El pensamiento histórico de Hume tiene interés por haber resaltado incluso de manera más eficaz que Burke una línea de crítica de Locke y su teoría del contrato. En este punto Ortega y Hume coinciden: la recusación del contrato político como fundamento de legitimidad del orden establecido. Con todo, aquí también la posición de Ortega está menos desarrollada que la de Hume. Pero lo cierto es que los dos entenderían que la posición de Locke es "ideal" en el sentido de abstracta, y no

\footnotetext{
${ }^{26}$ Tocqueville (2010), p. 266.
}

27 Tocqueville (2010), p. 466. 
tiene en cuenta la realidad histórica, y los dos tienden a hacer esta recusación desde el conocimiento de la historia y de la sociedad en su efectividad. En realidad, es una crítica que está en consonancia con las otras dos posiciones conocidas en las que Hume recorta el alcance de la razón: la irreductibilidad de las cuestiones de hecho a las relaciones de ideas y la imposibilidad de pasar del "ser" al "deber ser" Pero hay que añadir que en todo ello la dimensión escéptica de Hume se encuentra compensada por una creencia en la naturaleza como ya defendió Kemp Smith ${ }^{28 .}$.

En el caso de Hume, esta posición típica del pensamiento conservador se da al tiempo con una crítica de la religión y sobre todo del influjo que de hecho tuvo la religión en exacerbar el conflicto político del siglo XVII. Es moderno por reconocer que el fanatismo no proviene solo de la superstición, sino también del entusiasmo ${ }^{29}$. Culpabiliza a este último como sentimiento específicamente moderno de la discordia en la política inglesa que llega a la guerra civil. Por su parte, la idea de Ortega en su madurez de una razón histórica apuntaba a un conocimiento del contexto que superaría una razón que pudiera abstraer la noción de contrato. "Uno de los más graves errores del pensamiento 'moderno'... ha sido confundir la asociación, que es, aproximadamente, lo contrario de aquélla. Al revés, todo acuerdo de voluntades presupone la existencia de una sociedad" 30 .

\title{
4. Final
}

La rebelión de las masas es no sólo la entrada en la madurez de Ortega, sino una obra que dejaba abierto el futuro.

\begin{abstract}
¿Cual es la altura de nuestro tiempo? No es la plenitud de los tiempos, y, sin embargo, se siente sobre todos los tiempos sidos y por encima de todas las conocidas plenitudes. No es fácil de formular la impresión que de sí misma tiene nuestra época: cree ser más que las demás, y a la par se siente como un comienzo, sin estar segura de no ser una agonía. ¿Qué expresión elegiríamos? Tal vez ésta: más que los demás tiempos e inferior a si misma. Fortísima y a la vez insegura de su destino. Orgullosa de sus fuerzas y a la vez temiéndolas" ${ }^{31}$.
\end{abstract}

No estoy seguro de que fuera posible escribir esto hoy, en la medida en que sentimos, quizá, que el mundo digital y la globalización suponen una ruptura incluso más fuerte de lo que podía experimentar Ortega. Pero al tiempo con esas rupturas nos encontramos en un nuevo escenario que ofrece posibilidades

\footnotetext{
${ }^{28}$ D. Livingston (1976), p. 4 para un comentario valorativo de la aportación de Kemp Smith.

${ }^{29}$ Schmidt (2003), p. 277 y ss. Véanse las puntualizaciones de Pocock (1999), p. 238.

${ }^{30} \mathrm{OC}, \mathrm{VI}-935$.

${ }^{31}$ OC, IV-393.
} 
distintas. En cualquier caso, queda claro que para Ortega, en este momento de su obra, el futuro quedaba abierto. Cabía la posibilidad de que las minorías selectas se volvieran a imponer.

Pero vista su obra posterior solo en parte vale para el propio Ortega la idea de una nueva Europa que la segunda parte de La Rebelión postula, es decir un marco donde la superioridad de unas élites puede garantizar un nuevo equilibrio a la sociedad. La visión de César y de Fernando el Católico, que con Mirabeau Ortega excepcionalmente alaba, se tendría que aplicar a la Europa literalmente desquiciada de finales de los años '20 creando nuevas instituciones. Poco después de La Rebelión de las Masas Ortega llega a otros conceptos que caracterizan su pensamiento político tardío: la creencia frente a la idea, el uso, y con ellos la falta de legitimidad que la pérdida de creencia en la autoridad ocasiona. En este sentido, su obra última es en realidad la de un liberal bastante desengañado que ha perdido el contexto de las Meditaciones del Quijote en que la acción de una nueva generación era verosímil. Mientras Hume siente e implícitamente comunica el optimismo de la primera ilustración y la confianza de una bondad de la naturaleza que puede asegurar el curso de la historia por encima de la contingencia de los acontecimientos, la experiencia de Ortega de las crisis era distinta. No es solo un problema suyo o de la sociedad española, sino de todos, como Adorno, Arendt, Schmitt, Strauss y el último Bergson o Spengler vieron. Sus obras son testimonios de la crisis de los años '20, '30 y '40 y la conciencia de que la naturaleza o la convención no pueden ofrecer normas vinculantes en situaciones de alteraciones profundas. La idea de la armonía entre la sociedad y la naturaleza, entre las virtudes naturales y las virtudes artificiales, queda en tela de juicio ante la experiencia de la modernidad. 


\section{Referencias bibliográficas:}

Bricke, J (1996): Mind and Morality. An examination of Hume's Moral Psychology. Oxford University Press. Oxford.

Capaldi, N y Livingston, D (1990): Liberty in Hume's History of England. Kluwer Academic Publishers. Dordrecht.

Forbes, D (1975): Hume's Philosophical Politics. Cambridge University Press. Cambridge.

Hardin, R (2007): David Hume.- Moral and Political Theorist. Oxford University Press. Oxford.

Hume, D (2007): A Treatise of Human Nature. Edited by David Fate Norton and Mary J. Norton. The Clarendon edition of works of David Hume. Oxford

Hume, D (1999): An Enquiry concerning Human Understanding. Edited by Tom Beauchamp. Oxford University Press. Oxford.

Hume, D (1987): Essays moral, political and literary. Liberty Fund. Indianapolis Hume, D (1983): The history of England. Liberty Fund. Indianapolis.

Lewis, D (1969): Convention . A philosophical Study. Basil Blackwell. Oxford. Livingston, D (1976): "Introduction" a Hume: A re-evaluation. Fordham University Press, New York.

Ortega y Gasset, J (O.C.): Obras Completas. Taurus. Madrid 2004.

Sabl, A.: Hume's Politics. Coordination and Crisis in the History of England. Princeton University Press. Princeton and Oxford.

Salas, J de (2005): "Contrato social, contrato político y David Hume” en David Hume. Nuevas perspectivas de su obra. Editado por Gerardo López Sastre. Ediciones Castilla-La Mancha. Cuenca.

Schmidt, C (2003): David Hume. Reason in History. University Park. Pennsylvania. Pennsylvania State University Press.

Snare, F (2002): Morals, Motivation and Convention. Hume's influential doctrines. Cambridge University Press. Cambridge.

Tocqueville, A (2010): De la Democratie en Amérique. Bilingual edition. Edited by Eduardo Nolla. Translated by James T. Schleifer. Liberty Fund. Indianápolis. 
